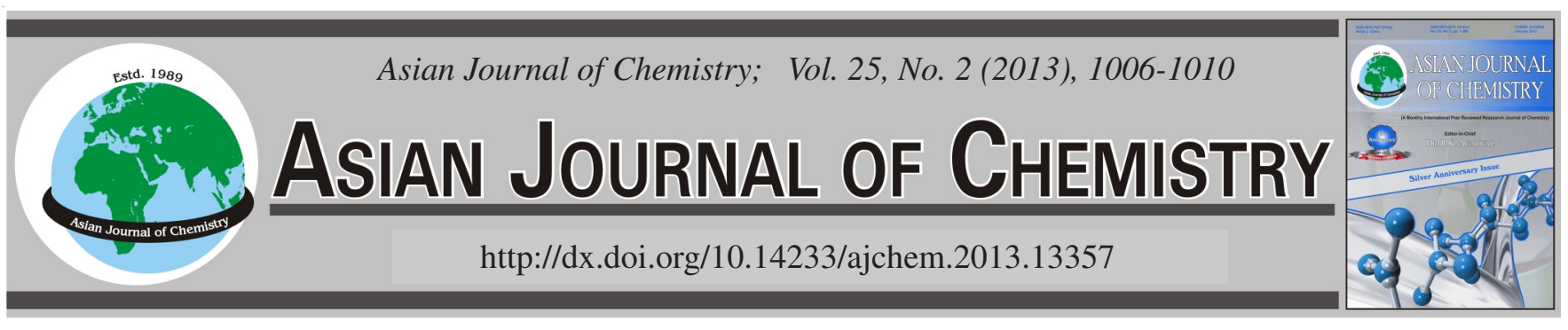

\title{
Effect of Gamma-Irradiation on Tocopherols and Free Fatty Acids in Walnut and Almond
}

\author{
Farhat Jubeen, Ijaz A. Bhatti*, Haq Nawaz Bhatti and Munir Ahmad Sheikh
}

Department of Chemistry and Biochemistry, University of Agriculture, Faisalabad, Pakistan

*Corresponding author: Fax: +92 41 9201103; Tel: +92 41 9200161-70 Ext. 3313; E-mail: ijazchem@ yahoo.com

\begin{abstract}
The present study was aimed to investigate the effect of storage period and $\gamma$ irradiation on tocopherols and free fatty acids composition in walnut and almond. Samples of nuts were randomly selected from the retail outlets of Faisalabad, Pakistan. The moisture content of the nuts was increased to $10 \pm 3$ and $16 \pm 3 \%$. The stored nut samples were exposed to $0,2,4,6$ and $8 \mathrm{kGy} \gamma$ radiation absorbed doses after a storage period of 12 weeks. The decrease in individual and total tocopherols of unirradiated nuts was significant during a storage period of 12 weeks and non significant in irradiated nuts. There was a significant increase in saturated fatty acids with a considerable decrease in unsaturated fatty acids during storage. In irradiated nuts, there was an increase in saturated fatty acids, considerable decrease in monounsaturated fatty acid and polyunsaturated fatty acids remained unchanged.
\end{abstract}

Key Words: Walnut, Almond, $\gamma$ Irradiation, Fatty acids, Tocopherol.

\section{INTRODUCTION}

Nuts are rich sources of oils. The tree nuts exhibit more than $50 \%(w / w)$ lipid fraction. A number of studies are carried out on nuts, highlighting their nutritional value, particularly lipid fraction and their health promoting attributes. Walnut (Juglans regia L.) is flourishing expansively right through the Himalayas at altitudes of 900-3300 m. It is valued as a dessert and dry fruit and greatly prized in ice-creams and confectionery. Regardless of its production and utilization in large magnitudes, its mycotoxin contamination has not been explored in detail so far $^{1}$. The almond tree (Prunus amygdalus) belongs to the Rosaceae family and is the most popular among tree nuts worldwide. This crop is highly valued for its fruit, aesthetic, nutritional and pharmaceutical properties. According to the already reported literature about different cultivars of walnut and almond, the lipid fraction of walnut and almond are 7075 and 50-60\%, respectively ${ }^{2-6}$. The compositional profile of lipid fraction extracted from the nuts show a little variation according to the climatic conditions of their habitat.

A complex of eight different homologues, four tocotrienols $(\alpha, \beta, \gamma, \delta)$ and four tocopherols $(\alpha, \beta, \gamma, \delta)$ is designated as vitamin $\mathrm{E}$. It is lipid-soluble vitamin. Biologically most active component of vitamin $\mathrm{E}$ is considered as a-tocopherol ${ }^{7}$. It is a pale yellow viscous oil that is insoluble in water but soluble in oils, fats and certain organic solvents, such as acetone, ether, alcohol and chloroform ${ }^{8}$. It also prevents the destruction of lipids by capturing free radicals and breaking lipid peroxidation chain reactions. The effects of oxidative stress, cardiovascular diseases, cancer, the aging process and atherosclerosis are claimed to be restrained by antioxidant activity of $\alpha$-tocopherol. Its action is supposed to be primarily by scavenging reactive oxygen species (ROS), particularly peroxyl radicals and forming resonance-stabilized tocopheroxyl radicals 9 .

Irradiation of food is employed as a cold food preservation process and has been comprehensively studied for its valuable and detrimental effects on food. Nuts have been found to contain numerous antioxidants and when exposed to ionizing radiation, formation of free radicals is reported. Antioxidative activity in the cashew nuts was found to reduce considerably by irradiation at $0.25-1.00 \mathrm{kGy}$ and subsequent storage ${ }^{10}$. Due to much debate about the safety of $\gamma$ irradiated food, a number of studies have been conducted to assess the after effects of $\gamma$ irradiation.

\section{EXPERIMENTAL}

Samples of walnut and almond were randomly collected from retail outlets of Faisalabad, Pakistan. The kernels (nuts without shells) of walnut and almond were purchased for this study. The initial moisture contents (MC) of walnut and almond were found to be 0.38 and $0.68 \%$, respectively. Moisture contents were determined following the method of USDA, $1978^{11}$. The moisture contents of the samples were adjusted to $10 \pm 3$ and $16 \pm 3 \%$ with tap water and stored in wooden containers. To avoid the loss of moisture from nuts, the containers were roofed with polythene films. During 1st, 2nd, 
4 th and 12 th week of storage, the nuts at both the moisture levels $(10 \pm 3$ and $16 \pm 3 \%$ ) were investigated for tocopherols as well as free fatty acids. After a storage period of 12 weeks, the nuts were undertaken $\gamma$ irradiation.

$\boldsymbol{\gamma}$-Irradiation of nuts: After 12th week of storage, $\boldsymbol{\gamma}$ irradiation was performed using Cs-137 in a $\gamma$-chamber (Gamma cell 3000) concaved in water as radiation source, at Nuclear Institute for Agriculture and Biology (NIAB), Faisalabad. The dose rate of the $\gamma$-irradiator was $0.6746 \mathrm{kGy} \mathrm{h}^{-1}$ having activity $2.7 \mathrm{KCi}$. All the samples were irradiated at ambient temperature $22 \pm 2{ }^{\circ} \mathrm{C}$. The samples were exposed at a distance of $2.5 \mathrm{~cm}$ from the source for 180, 360, 540 and $720 \mathrm{~min}$ for the absorbed doses of 2, 4, 6 and $8 \mathrm{kGy}$. The experiments were carried out for three replicates for each radiation dose and each nut at $10 \pm 3$ and $16 \pm 3 \%$ moisture levels. The irradiated ground and tree nuts were kept at a temperature of $2 \pm 2{ }^{\circ} \mathrm{C}$ until further analysis.

Extraction of fat: Fat was extracted at different time intervals during storage of unirradiated and irradiated nuts according to the method reported by Schreiber et al. ${ }^{12}$.

Tocopherol analysis: Tocopherol analysis was carried out according to the method suggested by Swiglo and Sikorska ${ }^{13}$. The samples were analyzed by injection into high performance liquid chromatograph. Mobile phase used was acetonitrile and methanol in the ratio of $1: 1$. Isocratic elution was done at a flow rate of $1.3 \mathrm{~mL} / \mathrm{min}$ and the amount of sample injected was 20 $\mu \mathrm{L}$. Fluorescence detector was used with an excitation wavelength at $295 \mathrm{~nm}$ and emission at $325 \mathrm{~nm}$. Qualitative as well as quantitative determination of $\alpha, \gamma$ and $\delta$ tocopherols was done by comparing their retention times with the corresponding standards and evaluating the area under each peak.
Free fatty acid composition: The free fatty acids compositions of control, unirradiated and irradiated walnut and almond were determined by gas chromatography by derivatizing free fatty acid into methyl esters. Fatty acid methyl esters were prepared by the method followed by Sheshata et al. ${ }^{14}$. The samples were analyzed by gas chromatograph (Perkin Elmer3920 attached with C-R4A chromatopac) at following operating conditions.

Statistical analysis: Each laboratory sample was divided into three analytical samples and then each sample was analyzed in triplicate and data are reported as mean $(\mathrm{n}=3 \times$ 3 ) \pm SD. An analysis of variance (ANOVA) was executed using Minitab 2000 version 13.2 statistical software (Minitab Inc. Pennsylvania, USA).

\section{RESULTS AND DISCUSSION}

Tocopherols content in tree and ground nuts: The tocopherols content of control, unirradiated and irradiated walnut and almond was estimated by high performance liquid chromatography, Table-1 represents the data obtained from triplicate analyses of lipid samples of walnuts during storage at different moisture levels. In walnut, lipid sample taken during first week of storage, $\alpha$-tocopherol was found to be the predominant isomer of vitamin $\mathrm{E}$ followed by $\delta$ and $\alpha$-tocopherols. This finding is in agreement with the tocopherols content reported in various cultivars of walnut ${ }^{15}$. The results are also in accordance with the tocopherol contents of almond stored for different time intervals, at two moisture contents as presented in Table-2. Almond, belongs to the family of tree nuts, but its tocopherol content is exactly opposite to that of walnut. The concentrations of the three tocopherol isomers follows the order $\delta<\gamma<\alpha$. This result is in accordance with dry nuts ${ }^{16,17}$.

TABLE-1

VITAMIN E $(\alpha, \delta$ AND $\gamma$-TOCOPHEROLS) LEVELS DURING STORAGE IN WALNUT AT DIFFERENT MOISTURE LEVELS

\begin{tabular}{cccccc}
\hline \multirow{2}{*}{$\begin{array}{c}\text { Moisture contents } \\
(\%)\end{array}$} & $\begin{array}{c}\text { Storage period } \\
\text { (week) }\end{array}$ & $\alpha$-Tocopherol & $\delta$-Tocopherol & $\gamma$-Tocopherol & Total \\
\cline { 3 - 6 } $10 \pm 3$ & Ist & $8.71 \pm 0.61$ & $25.61 \pm 0.62$ & $266.28 \pm 0.93$ & $300.61 \pm 1.7$ \\
& 2nd & $5.21 \pm 0.29$ & $22.57 \pm 0.33$ & $245.07 \pm 0.44$ & $272.86 \pm 1.9$ \\
4th & $3.03 \pm 0.08$ & $17.32 \pm 0.33$ & $224.44 \pm 0.38$ & $244.78 \pm 2.4$ \\
12th & $2.95 \pm 0.05$ & $6.52 \pm 0.05$ & $214.81 \pm 0.31$ & $224.29 \pm 0.88$ \\
\hline \multirow{2}{*}{$16 \pm 3$} & Ist & $8.71 \pm 0.61$ & $25.62 \pm 0.62$ & $266.28 \pm 0.93$ & $300.62 \pm 1.7$ \\
& 2nd & $4.29 \pm 0.34$ & $9.96 \pm 0.40$ & $225.25 \pm 0.65$ & $239.51 \pm 1.67$ \\
& 4th & $2.61 \pm 0.02$ & $5.82 \pm 0.02$ & $212.70 \pm 0.29$ & $221.14 \pm 1.41$ \\
*Mean \pm standard deviation $(\mathrm{n}=3)$ & $1.56 \pm 0.01$ & $1.96 \pm 0.04$ & $205.26 \pm 0.22$ & $208.79 \pm 1.40$ \\
\hline
\end{tabular}

TABLE-2

VITAMIN E $(\alpha, \delta$ AND $\gamma$-TOCOPHEROLS) LEVELS DURING STORAGE IN ALMOND AT DIFFERENT MOISTURE LEVELS

\begin{tabular}{|c|c|c|c|c|c|}
\hline \multirow{2}{*}{$\begin{array}{l}\text { Moisture contents } \\
\qquad(\%)\end{array}$} & \multirow{2}{*}{$\begin{array}{l}\text { Storage period } \\
\text { (week) }\end{array}$} & \multicolumn{4}{|c|}{ Tocopherol $\left(\mathrm{mg} \mathrm{kg}^{-1}\right)$} \\
\hline & & $\alpha$-Tocopherol & $\delta$-Tocopherol & $\gamma$-Tocopherol & Total \\
\hline \multirow{4}{*}{$10 \pm 3$} & Ist & $279.11 \pm 0.91$ & $15.61 \pm 0.46$ & $43.91 \pm 0.55$ & $338.63 \pm 2.25$ \\
\hline & 2nd & $238.71 \pm 1.45$ & $9.89 \pm 0.11$ & $32.01 \pm 0.65$ & $280.61 \pm 2.11$ \\
\hline & 4th & $194.16 \pm 1.61$ & $4.73 \pm 0.26$ & $27.58 \pm 1.10$ & $226.47 \pm 1.92$ \\
\hline & 12 th & $161.98 \pm 1.15$ & $1.77 \pm 0.45$ & $25.72 \pm 0.71$ & $189.47 \pm 1.53$ \\
\hline \multirow{4}{*}{$16 \pm 3$} & Ist & $279.11 \pm 1.24$ & $15.61 \pm 0.77$ & $43.91 \pm 0.51$ & $338.62 \pm 2.49$ \\
\hline & 2nd & $205.08 \pm 2.16$ & $6.63 \pm 0.62$ & $28.01 \pm 0.62$ & $239.73 \pm 2.45$ \\
\hline & 4th & $176.45 \pm 1.98$ & $3.78 \pm 0.81$ & $25.64 \pm 0.91$ & $205.87 \pm 2.03$ \\
\hline & 12th & $134.45 \pm 2.01$ & $1.01 \pm 0.01$ & $21.79 \pm 0.95$ & $157.25 \pm 2.61$ \\
\hline
\end{tabular}

*Mean \pm standard deviation $(\mathrm{n}=3)$. 
During storage period of 12 weeks, a decrease in tocopherol content was observed in all nut samples at both moisture levels. There was a significant change $(p<0.05)$ in individual and total tocopherol content of all nuts at both moisture levels. This finding is in consistence with the vitamin E component of rice bran reported in previous literature ${ }^{18}$. These authors also report that high destruction of vitamin E may be related to the amount of free fatty acids hydrolyzed by lipolytic enzymes in food or feed commodity. The loss of tocopherol content in nuts during storage may be attributed to loss of antioxidant activity as a natural phenomenon.

Effect of $\boldsymbol{\gamma}$-irradiation on tocopherols in stored nuts: The effect of different doses of $\gamma$-radiation ranging from 0-8 $\mathrm{kGy}$ on $\alpha, \gamma, \delta$ and total tocopherols in 12 week, stored walnut and almond oils was studied. The results are shown in Tables 3 and 4, respectively. For un-irradiated walnut samples, adjusted at low moisture levels, the values for $\alpha, \delta$ and $\alpha$ tocopherol were $2.955,6.517$ and $214.8 \mathrm{mg} \mathrm{kg}^{-1}$, respectively (Table-3). The values for $\alpha$ and $\delta$-tocopherol decreased gradually till $8 \mathrm{kGy}$ treatment. There was a slight variation in $\alpha$-tocopherol as evident from the data. There was also a decreasing trend in total tocopherol content. Similar observations were noted for walnut adjusted at high moisture level. For almond oil at low moisture level, the maximum decrease in $\alpha, \delta$ and $\gamma$-tocopherol and total tocopherol content observed at $8 \mathrm{kGy}$ were 130, 0.624, 20.809 and $151.44 \mathrm{mg} \mathrm{kg}^{-1}$, respectively. The similar observation was also noticed for irradiated almond oil at high moisture level. But the change in tocopherol contents was statistically non-significant.
The decreasing trend with the radiation treatment in tocopherols is in accordance with that reported in red meat, Turkey, vegetable oils, sage, thyme and oregano ${ }^{19-21}$. As vitamin $\mathrm{E}$ is known as the most radio-resistant of all the fat soluble vitamins, a number of authors had studied the effect of radiations on tocopherols in various foods. They establish different results according to the composition assayed, water activity and the radiation conditions ${ }^{22,23}$. The decreasing trend in tocopherol contents is interrelated to the degradation or quenching of free radicals generated by $\gamma$-irradiation.

Changes in free fatty acids profile in of ground and tree nuts during storage: Free fatty acids composition of the lipid component of control, unirradiated (during 1st, 2nd, 4th and 12th weeks of storage) and irraited walnut and almond was estimated qualitatively and quantitatively by GC/ FID. The results are shown in Tables 5 and 6.

The saturated fatty acids in walnut and almond are palmitic acid $\left(\mathrm{C}_{16: 00}\right)$ and stearic acid $\left(\mathrm{C}_{18: 00}\right)$. The unsaturated fatty acids are oleic acid $\left({ }_{\mathrm{C} 18: 1}\right)$, linoleic acid $\left(\mathrm{C}_{18: 2}\right)$ and linolenic acid $\left(\mathrm{C}_{18: 3}\right)$. The fatty acids profile of walnut was found to be composed of $12.66 \%$ saturated and $87.33 \%$ unsaturated fatty acids, which further constituted of $27.31 \%$ monounsaturated and $60.02 \%$ polyunsaturated fatty acids. In case of almond, only $10.62 \%$ saturated, $74.1 \%$ monounsaturated and $15.27 \%$ polyunsaturated fatty acids were estimated. However, in almond the oleic acid was the predominant fatty acid $(74.10 \%)$ and poly unsaturated fatty acids were approximately $15 \%$. The fatty acid profiles of the nuts revealed in the present study were in synchronization with a number of already published reports

TABLE-3

EFFECT OF $\gamma$-IRRADIATION ON VITAMIN E CONTENT IN WALNUT ADJUSTED AT DIFFERENT MOISTURE LEVELS

\begin{tabular}{|c|c|c|c|c|c|}
\hline \multirow{2}{*}{$\begin{array}{l}\text { Moisture contents } \\
\qquad(\%)\end{array}$} & \multirow{2}{*}{$\begin{array}{l}\text { Irradiation dose } \\
\qquad(\mathrm{kGy})\end{array}$} & \multicolumn{4}{|c|}{ Tocopherol $\left(\mathrm{mg} \mathrm{kg}^{-1}\right)$} \\
\hline & & $\alpha$-Tocopherol & $\delta$-Tocopherol & $\gamma$-Tocopherol & Total \\
\hline \multirow{5}{*}{$10 \pm 3$} & 0 & $2.95 \pm 0.25$ & $6.52 \pm 0.21$ & $214.21 \pm 1.21$ & $224.28 \pm 2.50$ \\
\hline & 2 & $2.71 \pm 0.61$ & $6.99 \pm 0.45$ & $212.82 \pm 1.55$ & $222.53 \pm 3.13$ \\
\hline & 4 & $3.29 \pm 0.04$ & $6.42 \pm 0.37$ & $216.88 \pm 1.05$ & $226.59 \pm 2.72$ \\
\hline & 6 & $2.57 \pm 0.21$ & $4.46 \pm 0.41$ & $211.87 \pm 1.42$ & $218.91 \pm 2.55$ \\
\hline & 8 & $1.47 \pm 0.01$ & $3.65 \pm 0.62$ & $201.15 \pm 1.20$ & $206.26 \pm 1.92$ \\
\hline \multirow{5}{*}{$16 \pm 3$} & 0 & $1.56 \pm 0.02$ & $1.96 \pm 0.41$ & $205.26 \pm 1.45$ & $208.79 \pm 1.94$ \\
\hline & 2 & $1.35 \pm 0.04$ & $1.60 \pm 0.25$ & $194.18 \pm 1.44$ & $197.13 \pm 2.41$ \\
\hline & 4 & $1.21 \pm 0.01$ & $1.21 \pm 0.11$ & $183.72 \pm 1.01$ & $186.14 \pm 2.76$ \\
\hline & 6 & $1.12 \pm 0.05$ & $0.86 \pm 0.21$ & $192.04 \pm 1.63$ & $194.01 \pm 3.38$ \\
\hline & 8 & $0.58 \pm 0.03$ & $0.63 \pm 0.15$ & $184.07 \pm 1.12$ & $185.28 \pm 1.51$ \\
\hline
\end{tabular}

TABLE-4

EFFECT OF $\gamma$-IRRADIATION ON VITAMIN E CONTENT IN ALMOND ADJUSTED AT DIFFERENT MOISTURE LEVELS

\begin{tabular}{|c|c|c|c|c|c|}
\hline \multirow{2}{*}{$\begin{array}{l}\text { Moisture contents } \\
\qquad(\%)\end{array}$} & \multirow{2}{*}{$\begin{array}{c}\text { Irradiation dose } \\
(\mathrm{kGy})\end{array}$} & \multicolumn{4}{|c|}{ Tocopherol $\left(\mathrm{mg} \mathrm{kg}^{-1}\right)$} \\
\hline & & $\alpha$-Tocopherol & $\delta$-Tocopherol & $\gamma$-Tocopherol & Total \\
\hline \multirow{5}{*}{$10 \pm 3$} & 0 & $161.98 \pm 1.01$ & $1.77 \pm 0.41$ & $25.72 \pm 0.54$ & $189.47 \pm 1.29$ \\
\hline & 2 & $158.12 \pm 1.31$ & $1.82 \pm 0.23$ & $24.97 \pm 0.27$ & $184.91 \pm 1.45$ \\
\hline & 4 & $163.40 \pm 1.45$ & $1.65 \pm 0.22$ & $25.74 \pm 0.45$ & $190.79 \pm 1.12$ \\
\hline & 6 & $160.97 \pm 1.04$ & $1.51 \pm 1.01$ & $22.43 \pm 0.27$ & $184.91 \pm 1.01$ \\
\hline & 8 & $130.01 \pm 1.05$ & $0.63 \pm 0.32$ & $20.81 \pm 0.55$ & $151.44 \pm 1.01$ \\
\hline \multirow{5}{*}{$16 \pm 3$} & 0 & $134.45 \pm 1.68$ & $1.01 \pm 1.64$ & $21.79 \pm 0.31$ & $157.25 \pm 1.74$ \\
\hline & 2 & $136.76 \pm 0.99$ & $0.99 \pm 0.07$ & $21.58 \pm 0.29$ & $159.33 \pm 2.15$ \\
\hline & 4 & $132.64 \pm 1.26$ & $0.65 \pm 0.02$ & $20.65 \pm 0.41$ & $153.94 \pm 2.02$ \\
\hline & 6 & $128.34 \pm 1.05$ & $0.74 \pm 0.02$ & $18.85 \pm 0.35$ & $147.93 \pm 2.41$ \\
\hline & 8 & $120.18 \pm 1.21$ & $0.51 \pm 0.01$ & $20.67 \pm 0.19$ & $141.36 \pm 1.81$ \\
\hline
\end{tabular}




\begin{tabular}{|c|c|c|c|c|c|c|c|c|}
\hline \multirow{2}{*}{$\begin{array}{l}\text { Moisture contents (\%) } \\
\text { Storage period (week) }\end{array}$} & \multicolumn{4}{|c|}{$10 \pm 3$} & \multicolumn{4}{|c|}{$16 \pm 3$} \\
\hline & 1 st & 2nd & 4th & 12 th & $1 \mathrm{st}$ & 2nd & 4th & 12th \\
\hline \multicolumn{5}{|c|}{ Fatty acids $(\mathrm{g} / 100 \mathrm{~g})$} & \multicolumn{4}{|c|}{ Fatty acids $(\mathrm{g} / 100 \mathrm{~g})$} \\
\hline 16:00 & $8.39 \pm 0.21$ & $9.32 \pm 0.15$ & $9.68 \pm 0.04$ & $9.85 \pm 0.65$ & $8.39 \pm 0.32$ & $9.74 \pm 0.01$ & $10.09 \pm 0.19$ & $10.31 \pm 0.71$ \\
\hline 18:00 & $4.26 \pm 0.01$ & $4.46 \pm 0.21$ & $5.18 \pm 0.24$ & $5.59 \pm 0.19$ & $4.27 \pm 0.08$ & $4.82 \pm 0.26$ & $5.48 \pm 0.71$ & $6.18 \pm 0.19$ \\
\hline 18:01 & $27.31 \pm 0.78$ & $26.97 \pm 1.67$ & $27.59 \pm 0.46$ & $27.97 \pm 0.11$ & $27.32 \pm 0.78$ & $25.36 \pm 0.38$ & $26.51 \pm 0.28$ & $28.70 \pm 1.7$ \\
\hline 18:02 & $47.52 \pm 0.51$ & $44.76 \pm 0.20$ & $41.42 \pm 0.2$ & $38.91 \pm 0.92$ & $47.52 \pm 1.04$ & $44.23 \pm 1.21$ & $40.16 \pm 0.94$ & $38.49 \pm 0.43$ \\
\hline 18:03 & $12.48 \pm 0.11$ & $12.28 \pm 0.12$ & $11.07 \pm 0.88$ & $9.62 \pm 0.83$ & $12.49 \pm 0.07$ & $11.14 \pm 0.39$ & $10.36 \pm 0.78$ & $9.18 \pm 0.46$ \\
\hline$\Sigma$ SFA & $12.66 \pm 0.25$ & $13.79 \pm 0.48$ & $14.87 \pm 0.44$ & $15.45 \pm 0.29$ & $12.67 \pm 0.12$ & $14.56 \pm 0.12$ & $15.57 \pm 0.61$ & $16.49 \pm 0.29$ \\
\hline$\Sigma$ UFA & $87.33 \pm 1.2$ & $84.03 \pm 1.05$ & $80.08 \pm 1.41$ & $76.50 \pm 1.08$ & $87.33 \pm 1.18$ & $80.73 \pm 1.00$ & $77.04 \pm 0.54$ & $76.37 \pm 0.78$ \\
\hline$\Sigma \mathrm{UFA} / \Sigma \mathrm{SFA}$ & 6.8 & 6.1 & 5.4 & 4.9 & 6.8 & 5.5 & 4.9 & 4.6 \\
\hline
\end{tabular}

*Mean \pm standard deviation $(n=3)$.

TABLE-6

CHANGES IN FREE FATTY ACIDS PROFILE IN ALMOND DURING STORAGE ADJUSTED AT DIFFERENT MOISTURE LEVELS

\begin{tabular}{|c|c|c|c|c|c|c|c|c|}
\hline \multirow{2}{*}{$\begin{array}{l}\text { Moisture contents (\%) } \\
\text { Storage period (week) }\end{array}$} & \multicolumn{4}{|c|}{$10 \pm 3$} & \multicolumn{4}{|c|}{$16 \pm 3$} \\
\hline & $1 \mathrm{st}$ & 2 nd & 4th & 12th & $1 \mathrm{st}$ & $2 \mathrm{nd}$ & 4th & 12th \\
\hline \multicolumn{5}{|c|}{ Fatty acids $(\mathrm{g} / 100 \mathrm{~g})$} & \multicolumn{4}{|c|}{ Fatty acids $(\mathrm{g} / 100 \mathrm{~g})$} \\
\hline 16:00 & $8.74 \pm 0.44$ & $9.36 \pm 0.26$ & $9.85 \pm 0.03$ & $10.05 \pm 0.1$ & $8.74 \pm 0.06$ & $9.74 \pm 0.04$ & $10.03 \pm 0.14$ & $10.22 \pm 0.29$ \\
\hline 18:00 & $1.89 \pm 0.03$ & $1.92 \pm 0.02$ & $2.07 \pm 0.03$ & $2.31 \pm 0.01$ & $1.89 \pm 0.02$ & $1.94 \pm 0.06$ & $2.32 \pm 0.04$ & $2.51 \pm 0.03$ \\
\hline 18:01 & $74.10 \pm 0.55$ & $72.78 \pm 0.52$ & $72.59 \pm 0.40$ & $74.42 \pm 0.15$ & $74.10 \pm 0.11$ & $73.12 \pm 0.32$ & $74.62 \pm 0.24$ & $75.01 \pm 0.45$ \\
\hline 18:02 & $14.99 \pm 0.12$ & $14.59 \pm 0.46$ & $14.85 \pm 0.88$ & $13.62 \pm 0.5$ & $14.99 \pm 0.03$ & $14.12 \pm 0.15$ & $13.06 \pm 0.87$ & $12.78 \pm 0.1$ \\
\hline 18:03 & $0.28 \pm 0.02$ & $0.27 \pm 0.04$ & $0.25 \pm 0.02$ & $0.22 \pm 0.02$ & $0.28 \pm 0.01$ & $0.27 \pm 0.06$ & $0.24 \pm 0.04$ & $0.22 \pm 0.03$ \\
\hline$\Sigma$ SFA & $10.62 \pm 0.07$ & $11.28 \pm 0.52$ & $11.91 \pm 0.04$ & $12.36 \pm 0.13$ & $10.62 \pm 0.93$ & $11.68 \pm 1.11$ & $12.34 \pm 0.48$ & $12.73 \pm 0.17$ \\
\hline$\Sigma$ UFA & $89.37 \pm 1.02$ & $87.64 \pm 1.08$ & $87.69 \pm 0.78$ & $88.27 \pm 0.83$ & $89.37 \pm 0.48$ & $87.51 \pm 0.40$ & $87.93 \pm 0.01$ & $88.01 \pm 0.44$ \\
\hline$\Sigma \mathrm{UFA} / \Sigma \mathrm{SFA}$ & 8.4 & 7.7 & 7.3 & 7.1 & 8.4 & 7.4 & 7.1 & 6.9 \\
\hline
\end{tabular}

*Mean \pm standard deviation $(\mathrm{n}=3)$

on oils extracted from different varities of edible nuts specially walnut and almond ${ }^{2,24-26}$.

The storage period of 12 weeks selectively affected the free fatty acids in the nuts. The concentrations of palmitic and stearic acids increased throughout during storage period in the nuts analyzed. The increase in saturated fatty acids was statistically significant. The concentration of monounsaturated fatty acid showed a little decrease during 2 nd and 4th weeks of storage. However, during 12th week of storage, there was a considerable increase in oleic acid concentration. The concentration of polyunsaturated fatty acids decreased throughout the storage period in the nuts analyzed. This leads to a corresponding decrease in $\Sigma U F A / \Sigma$ SFA (oxidation index) throughout storage period. The decrease in polyunsaturated fatty acids and increase in saturated fatty acids was more pronounced for nuts adjusted at high moisture level as clear from the data.
The behaviour of the free fatty acids during storage in nuts, reported in our study, was found to be in harmony with those reported rice bran and almond ${ }^{18,23,27}$.

Effect of $\boldsymbol{\gamma}$-irradiation on free fatty acids in ground and tree nuts: The results obtained from the irradiated nuts stored for 12 weeks at different moisture levels are presented for walnut in Table-7 and almond in Table-8, respectively. The content of total saturated fatty acids, monounsaturated fatty acids and polyunsaturated fatty acids in unirradiated walnut at low moisture level were 15.40, 27.97 and 48.53 (g/ $100 \mathrm{~g}$ ), respectively. After irradiation at $8 \mathrm{kGy}$, their respective values were $18.69,24.97$ and $48.48(\mathrm{~g} / 100 \mathrm{~g})$. The content of palmitic and stearic acid increased $(p<0.05)$ by irradiation with a corresponding decrease $(p<0.05)$ in oleic acid in all the nut samples. The polyunsaturated fatty acid content remained unchanged. The effect of $\gamma$-irradiation was more definite for

TABLE-7

EFFECT OF $\gamma$-IRRADIATION ON FREE FATTY ACIDS PROFILE IN WALNUT ADJUSTED AT DIFFERENT MOISTURE LEVELS

\begin{tabular}{|c|c|c|c|c|c|c|c|c|c|c|}
\hline $\begin{array}{c}\text { Moisture } \\
\text { contents } \\
(\%)\end{array}$ & & & $10 \pm 3$ & & & & & $16 \pm 3$ & & \\
\hline $\begin{array}{l}\text { Irradiation } \\
\text { dose }(\mathrm{kGy})\end{array}$ & 0 & 2 & 4 & 6 & 8 & 0 & 2 & 4 & 6 & 8 \\
\hline \multicolumn{11}{|c|}{ Fatty acids $(\mathrm{g} / 100 \mathrm{~g})$} \\
\hline $16: 00$ & $9.85 \pm 0.65$ & $11.02 \pm 0.86$ & $11.14 \pm 0.53$ & $12.27 \pm 1.33$ & $11.53 \pm 0.98$ & $10.31 \pm 0.7$ & $11.56 \pm 0.32$ & $11.68 \pm 0.21$ & $12.92 \pm 0.41$ & $12.08 \pm 0.30$ \\
\hline $18: 00$ & $5.59 \pm 0.19$ & $6.79 \pm 0.07$ & $6.74 \pm 0.15$ & $6.93 \pm 0.16$ & $7.17 \pm 0.65$ & $6.18 \pm 0.19$ & $7.49 \pm 0.36$ & $7.44 \pm 0.54$ & $7.62 \pm 0.17$ & $7.92 \pm 0.16$ \\
\hline 18:01 & $27.97 \pm 0.11$ & $25.91 \pm 0.16$ & $25.51 \pm 0.13$ & $26.34 \pm 0.20$ & $24.97 \pm 0.24$ & $28.70 \pm 1.7$ & $26.57 \pm 0.37$ & $26.18 \pm 0.29$ & $27.07 \pm 0.41$ & $25.63 \pm 0.64$ \\
\hline $18: 02$ & $38.91 \pm 0.92$ & $38.66 \pm 1.86$ & $38.42 \pm 0.41$ & $38.81 \pm 0.76$ & $38.67 \pm 0.95$ & $38.49 \pm 0.43$ & $38.23 \pm 1.2$ & $38.01 \pm 0.78$ & $38.41 \pm 0.94$ & $38.26 \pm 0.54$ \\
\hline $18: 03$ & $9.62 \pm 0.83$ & $9.67 \pm 0.07$ & $9.45 \pm 0.65$ & $9.42 \pm 0.32$ & $9.81 \pm 0.41$ & $9.18 \pm 0.46$ & $9.24 \pm 0.53$ & $9.10 \pm 0.20$ & $8.87 \pm 0.44$ & $9.34 \pm 0.39$ \\
\hline$\Sigma S F A$ & $15.45 \pm 0.29$ & $17.82 \pm 0.95$ & $17.89 \pm 0.15$ & $19.19 \pm 0.16$ & $18.69 \pm 0.12$ & $16.49 \pm 0.29$ & $19.06 \pm 0.21$ & $19.11 \pm 0.21$ & $20.54 \pm 0.26$ & $20.00 \pm 0.16$ \\
\hline$\Sigma$ UFA & $76.50 \pm 1.08$ & $74.24 \pm 0.63$ & $73.38 \pm 0.82$ & $74.57 \pm 1.02$ & $73.45 \pm 0.97$ & $76.37 \pm 0.78$ & $74.04 \pm 0.86$ & $73.29 \pm 0.74$ & $74.36 \pm 1.06$ & $73.23 \pm 1.05$ \\
\hline$\Sigma U F A / \Sigma S F A$ & 4.9 & 4.2 & 4.1 & 3.8 & 3.9 & 4.6 & 3.8 & 3.8 & 3.6 & 3.6 \\
\hline
\end{tabular}

*Mean \pm standard deviation $(n=3)$. 
TABLE-8

EFFECT OF $\gamma$-IRRADIATION ON FREE FATTY ACIDS PROFILE IN ALMOND ADJUSTED AT DIFFERENT MOISTURE LEVELS

\begin{tabular}{|c|c|c|c|c|c|c|c|c|c|c|}
\hline $\begin{array}{c}\text { Moisture } \\
\text { contents } \\
(\%)\end{array}$ & & & $10 \pm 3$ & & & & & $16 \pm 3$ & & \\
\hline $\begin{array}{l}\text { Irradiation } \\
\text { dose }(k G y)\end{array}$ & 0 & 2 & 4 & 6 & 8 & 0 & 2 & 4 & 6 & 8 \\
\hline \multicolumn{11}{|c|}{ Fatty acids $(\mathrm{g} / 100 \mathrm{~g})$} \\
\hline $16: 00$ & $10.05 \pm 0.10$ & $12.15 \pm 0.87$ & $11.87 \pm 1.57$ & $11.34 \pm 0.17$ & $12.91 \pm 1.50$ & $10.22 \pm 0.29$ & $12.35 \pm 0.06$ & $11.53 \pm 0.93$ & $11.53 \pm 0.93$ & $13.12 \pm 1.11$ \\
\hline 18:00 & $2.31 \pm 0.01$ & $2.56 \pm 0.71$ & $3.13 \pm 0.19$ & $2.59 \pm 0.46$ & $2.87 \pm 0.17$ & $2.51 \pm 0.03$ & $2.78 \pm 0.04$ & $3.52 \pm 0.37$ & $2.81 \pm 0.10$ & $3.13 \pm 0.16$ \\
\hline 18:01 & $74.42 \pm 0.15$ & $71.09 \pm 0.45$ & $68.95 \pm 0.53$ & $70.83 \pm 1.27$ & $69.94 \pm 0.33$ & $75.01 \pm 0.45$ & $71.65 \pm 0.76$ & $69.51 \pm 0.09$ & $71.38 \pm 0.20$ & $70.52 \pm 0.39$ \\
\hline $18: 02$ & $13.62 \pm 0.5$ & $13.79 \pm 0.52$ & $13.34 \pm 0.96$ & $13.58 \pm 0.04$ & $13.56 \pm 0.38$ & $12.78 \pm 0.1$ & $12.93 \pm 0.37$ & $12.52 \pm 0.21$ & $12.75 \pm 0.20$ & $12.72 \pm 0.41$ \\
\hline $18: 03$ & $0.22 \pm 0.02$ & $0.22 \pm 0.20$ & $0.22 \pm 0.02$ & $0.22 \pm 0.00$ & $0.23 \pm 0.19$ & $0.22 \pm 0.03$ & $0.22 \pm 0.03$ & $0.21 \pm 0.08$ & $0.21 \pm 0.06$ & $0.22 \pm 0.02$ \\
\hline$\Sigma$ SFA & $12.36 \pm 0.13$ & $14.71 \pm 0.86$ & $15 \pm 0.89$ & $13.93 \pm 0.69$ & $15.79 \pm 0.22$ & $12.73 \pm 0.17$ & $15.14 \pm 0.65$ & $15.05 \pm 0.17$ & $14.34 \pm 0.33$ & $16.25 \pm 0.10$ \\
\hline$\Sigma$ UFA & $88.27 \pm 0.83$ & $85.09 \pm 0.88$ & $82.51 \pm 0.63$ & $84.62 \pm 1.02$ & $83.73 \pm 0.99$ & $88.01 \pm 0.44$ & $84.80 \pm 0.45$ & $82.25 \pm 0.17$ & $84.34 \pm 0.30$ & $83.45 \pm 0.15$ \\
\hline$\Sigma U F A / \Sigma S F A$ & 7.1 & 5.8 & 5.5 & 6.1 & 5.3 & 6.9 & 5.6 & 5.5 & 5.8 & 5.1 \\
\hline
\end{tabular}

*Mean \pm standard deviation $(\mathrm{n}=3)$.

nuts adjusted at high moisture level. The increasing trend of saturated fatty acids and decreasing trend of monounsaturated fatty acid was more pronounced at higher $\gamma$-radiation doses $(6$ and $8 \mathrm{kGy}$ ) in comparison to that at low radiation doses ( 2 and $4 \mathrm{kGy})$. These findings of the effect of $\gamma$-irradiation on fatty acid profiles of walnut and almond are in concordance with walnut and lamb meat ${ }^{28,29}$.

There was a gradual decrease in oxidation index with increase in $\gamma$-radiation absorbed dose in the irradiated nuts. Due to greater influence of $\gamma$-radiation on fatty acid composition in nuts at high moisture level, the relative increase in oxidation index was also more evident at high moisture level. The oxidation potential of unsaturated fatty acids is higher according to the literature. The oxidation index of fatty acid can be used to calculate the extension of shelf life ${ }^{30}$. Lower the ratio, longer will be the shelf life of the food. On the whole, the rates of oxidation of fatty acids are approximately 1:10:100:200 for stearic acid, oleic acid and linoleic acid, respectively ${ }^{31}$.

\section{ACKNOWLEDGEMENTS}

The authors acknowledged the financial support of the Higher Education Commission, Pakistan for this study. The authors also appreciated the useful suggestion and technical support of Dr. M. Shahid, Dr. Zargham Khan and Dr. Zahoorul-Hassan.

\section{REFERENCES}

1. P.K. Singh and A.N. Shukla, J. Stored Prod. Res., 44, 169 (2008).

2. A. Cherif, K. Sebei, S. Boukhchina, H. Kallel, K. Belkacemi and J. Arulc, J. Am. Oil Chem. Soc., 81, 901 (2004).

3. H. Miraliakbari and F. Shahidi, J. Food Lipids, 15, 81 (2008).

4. P. Sanchez-Bel, I. Egea, F. Romojaro and M.C. Martinez-Madrid, LWT, 41, 442 (2008)

5. N.R. Grosso, V. Nepote and C.A. Guzman, J. Agric. Food Chem., 48, 806 (2000)

6 F. Satil, N. Azcan and K.H.C. Baser, Chem. Nat. Comp., 39, 257 (2003).

7. M.G. Traber, Biofactors, 10, 115 (1999).
8. P. Gyorgy and R.M. Tomarelli, Fed. Proc., 4, 155 (1945).

9. C.M. Sabliov and C.E. Astete, In ed.: N. Garti, Encapsulation and Controlled Release of Antioxidants and Vitamins, Delivery and Controlled Release of Bioactives in Foods and Nutraceuticals, CRC Press, New York, pp. 297-330 (2008).

10. M.G. Sajilata and R.S. Singhal, Radiat. Phys. Chem., 75, 297 (2006).

11. USDA, The Official United States Standards for Grain, US Department of Agriculrure, US Government Printing Office, Washington, DC (1978).

12. G.A. Schreiber, G. Schulzki, A. Spiegelberg, N. Hell and K.W. Bogl, J. AOAC. Int., 77, 1202 (1994).

13. A.G. Swiglo and Sikorska, J. Chromatogr. A, 1048, 195 (2004).

14. A.Y. Sheshata, J.M. Deman and J.C. Alexander, Can. Inst. Food Technol. J., 3, 85 (1970).

15. G.P. Savage, P.C. Dutta and D.L. McNeil, J. Am. Oil Chem. Soc., 76, 1059 (1999).

16. C.M.L. Ortiz, S.P. Moya, A.B. Sanahuja, S.E.M. Perez, N.G. Teruel and M.L.M. Carratala, J. Food Comp. Anal., 21, 144 (2008).

17. H. Miraliakbari and F. Shahidi, J. Food Lipids, 15, 81 (2008).

18. T.S. Shin and S. Godber, J. Agric. Food Chem., 44, 567 (1996).

19. S. Brandstetter, C. Berthold, B. Isnardy, S. Solar and I. Elmadfa, Food Chem. Toxicol., 47, 2230 (2009).

20. L. Lakritz, J.B. Fox Jr., J. Hampson, R. Richardson, K. Kohout and D.W. Thayer, Meat Sci., 41, 261 (1995).

21. S. Lalas, O. Gortzi, J. Tsaknis and K. Sflomos, Int. J. Mol. Sci., 8, 533 (2007).

22. World Health Organization, Safety and Nutritional Adequacy of Irradiated Food, Geneva, pp. 140-141 (1994).

23. P. Saänchez-Bel, M.C. Martinez-Madrid, I. Egea and F. Romojaro, J. Agric. Food Chem., 53, 2567 (2005).

24. S.J. Amara, S. Casal, J.A. Pereira, R.M. Seabra and B.P.P. Oliveira, J. Agric. Food Chem., 51, 7698 (2003).

25. M. Venkatachalam and S.K. Sathe, J. Agric. Food Chem., 54, 4705 (2006).

26. M. Kornsteiner, K.H. Wagner and I. Elmadfa, Food Chem., 98, 381 (2006).

27. T.S. Shin, J.S. Godber, D.E. Martin and J.H. Wells, J. Food Sci., 62, 704 (1997).

28. S.F. Mexis, A.V. Badeka, E. Chouliara, K.A. Riganakos and M.G. Kontominas, Inn. Food Sci. Em. Technol., 10, 87 (2008).

29. M.M.A. Cristina, P.J.L.C. Ribeiro, M.J.P. Trigo, A.J.I. Alfaia, M.L.F. Castro, C.M.G.A. Fontes, R.J.B. Bessa and J.A.M. Prates, Meat Sci., 77, 689 (2007).

30. S. Pershern, M. Breene and C. Lulai, J. Food Process. Preserv., 19, 9 (1995).

31. F. OKeefe, A. Wiley and A. Knauft, J. Am. Oil Chem. Soc., 70, 489 (1993). 